\title{
UUR SURERY
}

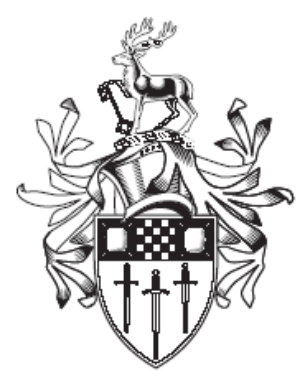

Discussion Papers in Economics

\section{LOBBIES, DELEGATION AND THE UNDER-INVESTMENT Problem in REgULATION}

\author{
By \\ Joanne Evans \\ (University of Surrey) \\ Paul Levine \\ (University of Surrey) \\ $\&$ \\ Fransesc Trillas \\ (Universitat Autonoma de Barcelona)
}

DP 20/06
Department of Economics University of Surrey Guildford
Surrey GU2 7XH, UK
Telephone $+44(0) 1483689380$
Facsimile +44 (0)1483689548
Web www.econ.surrey.ac.uk
ISSN: $1749-5075$




\title{
Lobbies, Delegation and the Under-investment Problem in Regulation
}

\author{
Joanne Evans \\ Paul Levine \\ University of Surrey \\ University of Surrey \\ Francesc Trillas \\ Universitat Autonoma de Barcelona
}

August 30, 2006

\begin{abstract}
A time-inconsistency problem in regulation often results in under-investment especially where there are high sunk costs in network industries such as electricity, gas, telecommunications and water. This paper provides a new perspective on this 'hold-up' problem facing the price regulation of a firm with market power where full commitment to a price regime is not possible. We compare a political equilibrium based on a voting model with lobbying with a delegation equilibrium, where a government can delegate to a particular 'type' of pro- or anti-industry regulator. Our analysis suggests two possible ways in which we may observe price regulation that encourages socially optimal investment in the absence of externally imposed regulatory commitment: first, there is less than total transparency in which voters receive an optimal amount of information and second, the decisions on price are delegated to a sufficiently, but not excessively, pro-industry regulator.
\end{abstract}

JEL Classification: L51

Keywords: under-investment, political equilibrium, capture, delegation. 


\section{Contents}

1 Introduction 1

2 Related Literature $\quad 4$

3 The Model $\quad 6$

3.1 The Firm . . . . . . . . . . . . . . . . . . . . 7

3.2 The Voters . . . . . . . . . . . . . . . . . . . . . . 8

3.3 The Parties and the Government . . . . . . . . . . . . . . . . . 10

4 The Political Equilibrium $\quad 12$

5 Rogoff-Delegation to an Independent Regulator $\quad 18$

6 Regulatory Governance in Practice and Empirical Evidence 23

6.1 Theoretical Results and Real World Practice . . . . . . . . . . . . . 23

6.2 Empirical Evidence . . . . . . . . . . . . . . . . . . . 26

$\begin{array}{lll}7 & \text { Conclusions } & 27\end{array}$

A Summary of Notation $\quad 33$

B A Simple Model of Binding Electoral Platforms 33

C The Choice of Contract at Stage 3 of the Lobbying Game 34 


\section{Introduction}

A long-standing time-inconsistency problem in regulation is under-investment arising from the regulator's incentive to exploit the sunk cost nature of the regulated firm's capital investment. Public ownership, or the direct regulation of investment avoid the problem, but there is now a broad consensus that such institutional arrangements provide poor incentives for efficiency and innovation. Rate of return regulation provides another possible solution, provided a commitment mechanism is in place that guarantees a 'fair rate of return'. Again such a 'low-powered' regulatory regime provides poor incentives to minimize cost, even if the fair rate guarantee can be made credible. By contrast, price regulation provides strong incentives for efficiency and, in this paper, we focus on this arrangement.

We examine the price regulation of a monopolist who can invest in period 1 in order to reduce network fixed costs in period 2. The efficiency of the firm is assumed to be observed so there is no adverse selection problem as, for example, in Laffont and Tirole (1993). The source of under-investment (the 'hold-up problem') is the incentive of the regulator to opportunistically lower the ex post regulated price once investment has occurred, though ex ante the firm has been promised a price sufficient to give an adequate return on its investment. This is a classic 'time inconsistency' problem which arises through the inability of the regulator to credibly commit to regulated prices over the two periods.

In practice governments may try to impose an external commitment mechanism on the regulatory authority through detailed legislation, but such legislation may not cover all subsequent contingencies. ${ }^{1}$ The theoretical literature offers a self-enforcing mechanism for solving the hold-up problem where, in a many period context, the regulator is deterred from opportunistic pricing by the subsequent investment response of the firm. But, as we discuss in the review of the next section, this device has severe limitations and the focus of this paper is therefore on alternatives.

Our paper provides a new perspective on the hold-up problem in regulation when a credible externally imposed commitment mechanism is not in place or a self-enforcing equilibrium is not possible. First, we develop a political economy model of price regulation where firms make investment choices. In this model the regulator is the government and is well-informed. However, only a proportion of the voters know the government's

\footnotetext{
${ }^{1}$ See section 6 .
} 
position on regulation policy and the remaining voters make a voting decision based on the general quality of the election campaign. This in turn depends upon the relative size of the parties' election expenditure creating an incentive for the parties and the firm to agree to implicit contracts that link political donations to a regulated price. We show that if a sufficiently high proportion of voters are badly informed, then a political equilibrium exists in which both parties (in our two-party system) are lobbied, receive political donations and implement a price regime that induces first-best investment. The commitment mechanism at play is the electoral mandate that parties must be seen to attempt to carry out. The political equilibrium is based on the voting model with lobbying of Grossman and Helpman (1996) that uses a common agency framework to overcome some of the limitations of Median Voter applications, such as the difficulties they have in dealing with multi-dimensionality, interest groups and asymmetric information. ${ }^{2}$

Our second contribution to the literature proposes another solution to the underinvestment problem that combines several features of the modern regulatory environment: government choice of a particular regulator over a period longer than the electoral cycle, the provision of independence to that regulator, and heterogeneity across regulators available. As with the political equilibrium, there is a commitment mechanism that drives this arrangement: the commitment (possibly imposed externally through a constitution) not to over-rule the prices set by the regulator. International institutions recommend setting up independent regulatory agencies: for example, in the European Union, the Gas and Electricity Directives oblige the member states to set up such institutions. This has triggered an academic debate on the determinants, impact and practical design of such independent agencies ${ }^{3}$. Thus in our set-up a government can appoint and credibly delegate to a particular type of regulator (or committee). Here a type refers to the preferences of the regulator being pro-industry (or anti-industry) in the sense of being pro-rent (or anti-rent) relative to those of the government. This solution to the under-investment problem is analogous to the idea, first proposed by Rogoff (1985), of delegating monetary policy to independent central bankers who are 'conservative' in the sense of being more inflation-averse than the government.

Our third contribution is an equivalence result: we show that, except for lobbying costs,

\footnotetext{
${ }^{2}$ See also Grossman and Helpman (2001).

${ }^{3}$ See Smith (1997), Gual and Trillas (2004, 2006) and Joskow (2006) for example
} 
the outcome obtained in a voting model with lobbying is, in economic terms, equivalent to the outcome obtained with an independent regulator, for certain values of the proportion of informed voters and the 'type' of regulator. Some voter lack of information and a regulator with preferences relatively favourable to the firm's rent may provide assurances for a firstbest level of investment. The importance of these assurances to investors increase with the returns to investment and the discount factor. However, regulatory independence and poorly informed voters have a cost in terms of higher prices, which may outweigh the advantages of first best investment. A political equilibrium with lobbying, besides the likely problems in terms of political legitimacy, has the additional drawback that political contributions may be significant and reduce the amount of resources available for investment.

This analysis suggests two potential mechanisms for alleviating the under-investment problem: first, voters receive just the amount of information that maximizes social welfare; and second, decisions on prices are delegated to a sufficiently, but not excessively, proindustry regulator. Rather than a normative result, this provides positive insights into observed regulatory structures. Separate regulatory authorities have been created in many countries in the recent past with considerable variation in their powers and profile. ${ }^{4}$ Two possible roles are suggested for them here: a separate authority that provides voters with the 'right' amount of information on regulatory policy (and then it is the politicians who actually fix the prices, in imperfect collusion ${ }^{5}$ with firms), or a fully independent regulator of the optimal 'type' to whom the government delegates price decisions.

The rest of this paper is organized as follows: Section 2 discusses related literature. Section 3 sets out the model. Section 4 derives a political equilibrium. Section 5 compares this with a delegation equilibrium. Section 6 compares the three possible solutions to the hold-up problem - externally imposed commitment to regulated prices, lobbying and delegation, provides real world examples and discusses empirical evidence. Section 7 concludes.

\footnotetext{
${ }^{4}$ See International Telecommunications Union (2002) and Gual and Trillas (2004, 2006).

${ }^{5}$ Imperfect, because a fraction of voters is informed, and hence their welfare must be taken into account. See Section 2.
} 


\section{Related Literature}

A number of studies have examined self-enforcing equilibria which can sustain first-best investment under price regulation. In a complete information many-period context, Salant and Woroch (1992), and Gilbert and Newbery (1994) (see also Newbery, 1999, chapter 2) show that outcomes at or close to first-best levels of investment can be sustained as a subgame-perfect trigger-strategy equilibrium. Unfortunately, the game-theoretic literature raises well-known problems with this approach. ${ }^{6}$

If we allow for asymmetric information in the form of incomplete information on the part of the firm regarding the type of regulator, then the existence of 'strong' regulators who like to commit, or are constrained by exogenous devices such as legislation to honour commitments, opens the door to reputational equilibria in which the regulator over time builds up a reputation with the firm for commitment. Such theoretically sound equilibria can again sustain the levels of investment close to the first-best. This device is technically similar to the trigger-strategies and it works well (in the sense that an equilibrium can be shown to exist) in other settings such a monetary policy. However for price regulation, Levine et al (2005) find that such a reputational equilibrium with optimal investment may not exist if there exists a combination of a low depreciation rate of capital, a low growth of consumer demand and a degree of short-sightedness on the part of the regulator. The reason for this result is that once a large investment project has been completed, the punishment for revealing one's type as a 'weak' regulator by reducing the regulated price, namely the withdrawal of future investment, only impacts gradually over time as capital depreciates and depends on the need for more capacity to meet increasing demand. If the latter effects are small and discounting by the regulator is high then the punishment is small and the incentive to deviate from the ex ante regulated price is large.

\footnotetext{
${ }^{6}$ These problems are first, the length of the punishment phase (usually infinity) is arbitrary. There exists an infinite number of such equilibria, one for each length of punishment. Even if the two players can coordinate on the best of these equilibria, there is a second more serious problem: the equilibrium is not 'renegotiation-proof'. The players always have an incentive to renegotiate (i.e., re-coordinate) after a deviation occurs, rather than carry out the punishment. This questions the credibility of trigger-strategy equilibria, even though they are sub-game perfect. (But see al-Nowaihi and Levine (1994) who, in the context of a monetary policy game, argue for a refinement they term 'chisel-proofness', to resolve this difficulty.)
} 
Spulber and Besanko (1992), in the context of environmental regulation, use the idea of Rogoff-delegation to develop a model where a president is shown to make credible commitments to future agency actions by choosing an agency director whose preferences over consumer and firm interests differ from his own. The divergence between the president's preferences and those of the desired agency director then depend on the agency's ability to make credible commitments. Spulber and Besanko point out that delegation is an imperfect mechanism because administrators are chosen before economic parameters are observed and before agency actions are taken. ${ }^{7}$

The idea that full information, in a regulatory setting, is not necessarily good is not new. There is a literature that shows that the introduction of private information on the part of the firm can alleviate the hold-up problem even where the price-setting regulator has complete discretion. Then the regulator in designing its 'revelation mechanism' may prefer ex ante not to receive information ex post because if she receives information she will expropriate the rent of the efficient type firm and hence the firm will have no incentives to reveal its type. Besanko and Spulber (1992), and the derivative paper Urbiztondo (1994) study this problem under the assumption that the firm has private information about cost or demand conditions. They show that in a sequential equilibrium underinvestment can be alleviated, at least for the efficient type of firm who is the recipient of informational rent. Laffont and Tirole (1993, chapter 11) arrive at a similar result in a model of regulatory capture where regulator and firm collude to send incorrect information back to the government (see also Armstrong and Sappington, 2003). But solutions to this regulatory problem that rely, indeed make a virtue of asymmetric information, still leave the question of what happens when regulators are well-informed about the firm. This is the focus of our paper.

Besley and Coate (2003) develop and test a model where regulators that are directly

\footnotetext{
${ }^{7}$ Boyer and Laffont (1999) analyze delegation in a regulatory setting from a different perspective. They characterize the conditions under which a biased environmental policy conducted by changing majorities who have a detailed knowledge of the economic outlook (proxied by the social cost of public funds) when they take decisions, is superior to an ex ante social welfare maximizing, but inflexible, environmental policy imposed by the constitution, drafted when that detailed knowledge is not available. We also touch on the costs and benefits of writing precise regulatory rules in the legislation when we discuss the Chilean case in Section 6 .
} 
elected by the voters are pro-consumer. In US states where the regulators, rather than directly elected, are appointed, voters are less informed. Their evidence shows that prices are lower in those states that elect their regulator than in those where the regulator is appointed by politicians. They also show that investment is higher in states that appoint the regulator. In common with our approach, they also stress the effect of voters' information on lobbying and policy determination.

The idea that some degree of capture may be necessary is not new either. Armstrong and Vickers (1996, p. 303) argue as follows:" "As to the question of industry-specific regulatory bodies versus ones with wider scope, we do not see decisive arguments either way. The danger of capture might argue against industry-specific bodies, but a degree of capture might enhance the credibility of commitment to allow an adequate return on investment." The possibility of capture is a well recognized feature ${ }^{9}$ of regulated sectors with privately owned firms. ${ }^{10}$

\section{The Model}

We follow much of the literature on dynamic regulation (see, for example, Laffont and Tirole (1993)) in adopting a two-period model. This modelling strategy merits some discussion. First, as we have already discussed, we confine ourselves to either an implicit contract of the firm with the political parties, or to delegation to an independent regulator. The possibility of avoiding the hold-up problem rests with one or other of these channels. We do not pursue a reputational solution through the repeated play of the game and the build-up of a reputation for commitment with the firm to an ex ante price regime. This solution would require us to go beyond the two-period structure; but as we have argued in the previous section such an equilibrium may not exist in a regulatory setting. Second, as we elaborate below in Subsection 3.3, our Grossman-Helpman framework relies on the

\footnotetext{
${ }^{8}$ They make this claim in the context of the analysis of the right policies in regulation and liberalization to alleviate under-investment in sunk assets, which the authors view as the main problem transition countries face in the reform of telecommunications.

${ }^{9}$ Both theoretically (see Laffont and Tirole, 1993) and empirically (see for example Duso, 2005).

${ }^{10}$ Other studies which convey the idea of the existence of an optimal (positive) degree of capture in the presence of other imperfections include Spiller (1990), Che (1995), Salant (1995), de Figueiredo et al. (1999), Sloof (2000), and Grossman and Helpman (2001).
} 
binding character of the electoral platform (though there is implementation uncertainty that political parties cannot avoid). Third, the two-period structure is not as restrictive as it may at first seem, since the two 'periods' can be of a different duration (see Subsection $3.1)$.

In both the lobbying equilibrium of this section and the delegation equilibrium of the next section the model has a number of core features in common. There is no production in period 1 but the firm incurs a fixed cost of maintaining its inherited capital. In period 1 the firm can invest to lower these fixed costs in period 2. The policymaker is fully informed about the firm so no information-revealing mechanism is required ${ }^{11}$.

Consider now the lobbying equilibrium. There are two parties, say 'Left' (L) and 'Right' (R). The regulated company is the only organized interest group or lobby in this economy. In period 1 the firm, in anticipation of the regulated phase in period 2, as well as investing to lower fixed costs, spends resources to capture the policy platforms of two competing parties although it does not have a prior preference for any of these two. A fixed proportion of voters are informed and vote for a party strictly on the basis of the effect of its policy on their utility. The rest of the voters are uninformed and their support for a party depends on the intensity of its campaign. This, in turn, depends on contributions from the lobby. The details of the rest of the set-up are as follows. The notation employed throughout the paper is summarized in Table 1 in Appendix A.

\subsection{The Firm}

In period 1 the firm can devote an amount $s^{j} \geq 0, j=L, R$ to lobby party $j$ which sets pricing policy $p^{j}$ in period 2. The two 'periods' can be of a different duration. In our lobbying equilibrium period 1 would be a campaigning period (say one year) in which firms lobby parties, and choose their investment, and elections take place. Period 2 would then be the period of office coinciding with the production period, say 4-5 years. The discount factor adopted must be carefully interpreted in this light and can exceed unity (see Laffont and Tirole (1993), chapter 9 where they discuss the 'large discount case'). As well as devoting resources to lobbying, the firm can invest in period 1 to lower costs in

\footnotetext{
${ }^{11}$ Levine and Rickman (2002) examine the hold-up problem with delegation where there is private information on the part of the firm regarding its cost structure
} 
period 2. In period 2 the firm produces a quantity $q^{j}=\psi\left(p^{j}\right)$ of a homogeneous good at a marginal cost $c$ where $\psi(\cdot)$ is the inverse demand curve. The profits in periods 1 and 2 are

$$
\begin{aligned}
\Pi_{1}=\Pi_{1}\left(i, s^{L}, s^{R}\right) & =-k-i-s^{L}-s^{R} \\
\Pi_{2}=\Pi_{2}\left(p^{j}, i\right) & =\left(p^{j}-c\right) \psi\left(p^{j}\right)-k+f(i) ; j=L, R
\end{aligned}
$$

respectively, depending in the second period on which party is elected, where $k$ are fixed costs in the first period, $i$ is monetary investment in period 1 which leads to a lowering of fixed cost of $f(i)$ in period 2. We assume $f^{\prime}>0, f^{\prime \prime}<0$ and $f^{\prime}(0)=\infty$.

The firm in period 1 maximizes the expected discounted sum of two-period profits. Suppose first that the elected party has previously rejected the firm's lobby; then in period 2, given i, it chooses $p$ to maximize consumers' net surplus $W(p)$, subject to the firm's second-period participation constraint $\Pi_{2}(p, i) \geq 0$. The standard result of this optimization problem is that the constraint binds, so that $\Pi_{2}(p, i)=0$ which determines $p=p(i)$ and output $q=\psi(p(i))=q(i)$. Then, since there is no incentive to invest, we must have that $i=0$ is chosen by the firm in period 1. This should be compared with the first-best investment outcome. Irrespective of the price regime which determines the distribution of benefits between the firm and consumer, the first-best investment must minimize discounted fixed costs $k-i+\delta f(i)$ at a level satisfying the first-order condition

$$
\delta f^{\prime}(i)=1
$$

where $\delta$ is the discount factor. Denote the first-best investment level by $i=i^{F B} \cdot{ }^{12}$

\subsection{The Voters}

There are two types of voters: informed and uninformed. Informed voters, who are a proportion $\theta$ of the population, are agents who know and understand the parties' positions on regulatory policy. When they vote, they know that parties commit to their electoral platforms, which they have previously agreed with the lobby (the firm): elections take place after parties accept or reject lobbying conracts (see timing of the game, Section 4). Informed voters derive utility

$$
u^{i}\left(p^{j}\right)=d W\left(p^{j}\right)+\phi(j) \omega^{i}, \text { for } j=L, R
$$

\footnotetext{
${ }^{12}$ Note that $i^{F B}>0$ and $\delta f\left(i^{F B}\right)-i^{F B}>0$ are ensured by the properties of $f(\cdot)$.
} 
where $W\left(p^{j}\right)$ is the net consumer surplus from pricing policy $p^{j}$, and we define the function $\phi(\cdot)$ by $\phi(L)=0$ and $\phi(R)=1$. In (4), $d>0$ denotes a measure of the importance of regulatory policy for the voters' decisions and $\omega^{i}$, unknown to the parties, denotes the $e x$ ante bias of an informed individual for party $R$ before the electoral campaign and before the policy announcement. In other words, $\omega^{i}$ reflects the informed voters' preferences for the immutable characteristics and program of the parties.

The parties cannot observe the ex ante proclivities of any particular voter, although they presume these to be drawn from a known cumulative distribution $F\left(\omega^{i}\right)$. In particular, the party bias is distributed according to a uniform distribution in the interval $\left[-\frac{1}{2}-a, \frac{1}{2}-a\right]$, where $a$ reflects an a priori advantage for party $L$. Any one of these informed voters votes for party $L$ or $R$ taking into account the difference in the utility she derives from $p^{L}$ and $p^{R}$ and taking into account her a priori preferences for one of the parties. It follows from (4) that an informed voter prefers party $L$ if $d\left[W\left(p^{L}\right)-W\left(p^{R}\right)\right]>\omega^{i}$. This defines the critical value $\widetilde{\omega}$ as:

$$
\widetilde{\omega}=d\left[W\left(p^{L}\right)-W\left(p^{R}\right)\right]
$$

Then all informed voters with values of $\omega^{i}<\widetilde{\omega}$ will vote for party $L$, and all the rest for party $R$. Thus from the parties' point of view there is a probability

$$
F[\widetilde{\omega}]=\int_{-\frac{1}{2}-a}^{\widetilde{\omega}} d i=\frac{1}{2}+a+d\left[W\left(p^{L}\right)-W\left(p^{R}\right)\right]
$$

that the informed individual $i$ will vote for party $L$. Thus the expected proportion of the electorate that is informed and votes for party $L$ is given by $\theta\left[\frac{1}{2}+a+d\left(W\left(p^{L}\right)-W\left(p^{R}\right)\right]\right.$.

Now consider uninformed voters, constituting a proportion $(1-\theta)$ of the population, who do not know about the regulatory policy platforms of any of the parties. Let $\omega^{\text {un }}$, unknown to the parties, describe the ex ante preferences of an uninformed voter for party $R$ before the electoral campaign. These individuals decide their votes according to the impression that they get from the intensity or quality of the electoral campaigns. In this sense, the electoral campaigns are not informative. The intensity/quality $h^{j}$ of party $j$ 's campaign depends on the firm's support to this party in the following form: $h^{j}\left(s^{j}\right)=$ $b s^{j}, j=L, R$. A typical uninformed voter derives utility

$$
u^{u n}\left(h^{j}\right)=b s^{j}+\zeta(j) \omega^{u n} \text { for } j=L, R
$$


where we define the function $\zeta(\cdot)$ by $\zeta(L)=0$ and $\zeta(R)=1$. As for the informed voters, they vote for party $L$ if $u^{u n}\left(h^{L}\right)-u^{u n}\left(h^{R}\right)>\omega^{u n}$. Assuming $\omega^{u n}$ has the same distribution as $\omega^{i}$, the expected proportion of the voters that are uninformed and that vote for party $L$ is given by $(1-\theta)\left[\frac{1}{2}+a+b\left(s^{L}-s^{R}\right)\right]$.

\subsection{The Parties and the Government}

The Parliament is elected with proportional representation. Parties are assumed to carry out their electoral mandate. ${ }^{13}$ This is the underlying commitment mechanism that solves or at least alleviates the hold-up problem in the political equilibrium. To explain commitment to electoral platforms as a self-enforcing equilibrium requires us to go beyond the 2-stage game and think again in terms of a reputational equilibrium in which parties build up a reputation for commitment in general. The difference now is that the reputationbuilding is with the electorate, not the firm, and the punishment is a loss of votes, not a withdrawal of investments. Reputational equilibria based on loss of votes are more viable than the latter because punishment from loss of reputation is immediate (you lose the next election). Also the electoral gains from not implementing any particular platform, such as regulatory policy as in this paper, are likely to be small as this is a small part of the party's overall policies, but the damage with respect to a loss of reputation for commitment may be substantial because they extend to all areas of policy. In Appendix B we provide a simple model to formalize these ideas.

Parties have no ideological preferences and simply seek to maximize their vote share, or equivalently its representation in the Parliament, which with the maintained assumptions for party $L$ is:

$$
P^{L}=\frac{1}{2}+a+\theta d\left[W\left(p^{L}\right)-W\left(p^{R}\right)\right]+(1-\theta) b\left(s^{L}-s^{R}\right)
$$

and for party $R$ is $P^{R}=1-P^{L}$, given the nature of the two party system. We interpret (8) as the electoral support for the regulation policy of party L. It implies that incumbent L party has an advantage $(a>0)$, and raising the consumer surplus of informed voters under policy $\mathrm{L}$ relative to $\mathrm{R}$ (the second term) and the relative lobbying of $\mathrm{L}$ (the third

\footnotetext{
${ }^{13}$ In Section 6 below we present three examples (UK, Chile, Spain). In each of these countries the main political parties announce their platforms on regulatory policies and we are not aware of any significant pledge that they have not honoured, at least on the broad contours of policy.
} 
term) increases the chances of winning. The constant $d>0$ and the constant $b>0$, introduced in (4) and (7) make all terms in (8) dimensionless.

The firm anticipates that the legislature adopts the regulatory policy $p^{L}$ with probability $\nu\left(P^{L}\right)$ and the regulatory policy $p^{R}$ with probability $1-\nu\left(P^{L}\right)$. The ex ante, two-period objective function of the firm now becomes

$$
\Theta=\Pi_{1}\left(i, s^{L}, s^{R}\right)+\delta\left[\nu\left(P^{L}\right) \Pi_{2}\left(p^{L}, i\right)+\left(1-\nu\left(P^{L}\right)\right) \Pi_{2}\left(p^{R}, i\right)\right]
$$

Although parties endeavor to carry out their regulatory mandate, we introduce a degree of implementation uncertainty, captured by the function $\nu\left(P^{L}\right)$, for which we make the following assumptions:

1) $\nu^{\prime}>0$

2) $\nu\left(\frac{1}{2}\right)=\frac{1}{2}$

3) $\nu^{\prime \prime}>0$ for all $P^{L}<\frac{1}{2}$ and $\nu(0)=0$.

4) $\nu^{\prime \prime}<0$ for all $P^{L}>\frac{1}{2}$ and $\nu\left(P^{L}\right) \rightarrow 1$ as $P^{L} \rightarrow \infty$.

Properties 1) and 2) are obvious requirements, while 3) and 4) ensure that $\nu$ can be interpreted as a probability. Having a continuous $\nu(\cdot)$ function allows us to keep the possibility of the two parties being lobbied, which is quite realistic (many big regulated firms contribute to the two big parties in the US, the UK, and many other countries). ${ }^{14}$ It could alternatively be assumed that $\nu=1$ if $P^{L}>P^{R}$. Then if $a>0$ only the leftist party is lobbied, since the analysis of stage 2 below establishes that $P^{L}=\frac{1}{2}+a$. The rightist party captures less than half of the vote and the legislature has zero probability of adopting the policy of party $\mathrm{R}$. Conversely, if $a<0$, then only the rightist party is lobbied. If $a=0$, then $P^{L}=P^{R}=\frac{1}{2}$, and therefore $\nu\left(\frac{1}{2}\right)=\frac{1}{2}$.

Another possibility would be to assume that the parties instead of maximizing their vote share (as we assume), behave as to maximize their probability of winning, reflecting a system of strict majority rule. In the appendix of Grossman and Helpman (1996) it is shown that the equilibrium policy in such a scenario is the same as when parties maximize their vote share, in the symmetric case where neither party has an a priori advantage (with our notation, in the case $a=0$ ). These authors describe this situation as follows:

\footnotetext{
${ }^{14}$ For example, "between 1988 and 1996, Enron and its officers donated $\$ 1.9$ million to congressional and presidential candidates and to political parties, including $\$ 527,000$ in 'soft money' (loosely regulated donations made directly to a party) to the Republican and Democratic parties." (Fox, 2003, p. 111).
} 
"With equal popularity, the platform that emerges in a symmetric equilibrium when the legislature operates by strict majority rule and parties maximize their chances of winning a majority is the same as the platform that emerges in a symmetric equilibrium when parties maximize their representation in the legislature and a minority platform has some chance of being implemented."

Our assumption that parties maximize their vote share with implementation uncertainty reflects more common situations where a strict majority rule may not always hold, for example because parties may fail to implement their platform because of dissenting party members in the elected assembly embracing the policy of the opposite party (or members of Parliament failing to turn out at a crucial vote in the event of a very narrow majority). This interpretation amounts to assuming that the only possible policies are those sponsored by a party, based on the realistic notion that individual members of Parliament do not have the ability to impose their own policies in the Parliament's agenda. Implementation uncertainty may also be interpreted more generally as a reduced form of a proportional electoral system where there are other small parties apart from the two main ones; then if the majority party does not have an overall majority, its platform may not be implemented as originally designed, but has to find compromises with other parties' platforms, or even the small parties may support the platform of the second largest party.

\section{The Political Equilibrium}

Reflecting the observation that investment projects cover a longer period than parliaments, we assume that the investment decision is chosen before the price and political donation agreements between the firm and the parties. The timing of events is then as follows:

1. At the beginning of period 1 , the firm inherits a capital stock with per period fixed costs $k$.

2. The firm chooses investment $i$.

3. The firm offers price and donation contracts, $\left(p^{j}, s^{j}\right)$, to parties $j=L, R$.

4. The parties independently accept or refuse offers. By the end of this stage either no contract, or only one contract with the incumbent L-party, or contracts with both 
parties have been agreed.

5. The election takes place.

6. In period 2, the legislature either implements $p=p^{j}$ decided at event 4 with probability $\nu\left(P^{j}\right)$, for $j=L, R$, or $p=p(i)$, where $p(i)$ is a solution to $\Pi_{2}(p, i)=0$, if the elected party refused a contract. Output is produced at marginal cost $c$ and fixed cost $k-f(i)$, where $f(0)=0$, to satisfy demand $\psi\left(p^{j}\right)$ or $\psi(p)$ depending on the existence of a contract.

In this dynamic game of full information, the appropriate equilibrium concept is a backward induction equilibrium, starting at stage 6 :

\section{Stage 6: Production in Period 2.}

The regulator implements $p^{j}$ for party $j=L, R$ resulting in second-period profits given by (2). If the contract was turned down by the winning party, then $\Pi_{2}(p(i), i)=0$ with $p=p(i)$.

\section{Stage 5: The Election.}

The election takes place which the incumbent L party wins with probability $P^{L}$ and the R party with probability $1-P^{L}$, where $P^{L}$ is given by (8).

\section{Stage 4: Acceptance or Rejection of Contract by Parties.}

Party L always has the option of refusing the lobby's offer, forgoing the political contribution and 'holding-up' investment by implementing the minimum price necessary to satisfy the firm's participation constraint, $p(i)$ where $\Pi_{2}(p(i), i)=0$. Then from (8) with $p^{L}=p(i)$ and $s^{L}=0$ it captures the share of votes

$$
P^{*}=\frac{1}{2}+a+\theta d\left[W(p(i))-W\left(p^{R}\right)\right]+(1-\theta) b\left(0-s^{R}\right)
$$

It follows that if the firm wants to affect the regulated price, it needs to provide the $\mathrm{L}$ party with sufficient funds to obtain votes $P^{L} \geq P^{*}$. From (10) and (8) the condition for this is

$$
s^{L} \geq \frac{d \theta}{b(1-\theta)}\left[W(p(i))-W\left(p^{L}\right)\right]
$$

A similar argument applies to party $\mathrm{R}$ so we arrive at

$$
s^{j} \geq \frac{d \theta}{b(1-\theta)}\left[W(p(i))-W\left(p^{j}\right)\right] ; \quad j=L, R
$$




\section{Stage 3: Choice of Contracts.}

The firm chooses $\left(p^{j}, s^{j}\right)$ to maximize $\Theta$ given by (9), subject to (12). Donations must be sufficient to induce one or both parties to accept the lobby's offer. At the same time, in choosing whether to offer the party a political contract, the firm will take into account the investment that took place at stage 2 . First, suppose that investment $i=i^{L}$ took place. The firm will then offer a contract $p^{j}$ iff this is preferable to no contract (in which case $p=p\left(i^{L}\right)$, recalling that $p(i)$ is the price at which $\left.\Pi_{2}(p, i)=0\right)$; i.e., iff

$$
s^{L}+i^{L} \leq \delta \nu\left(P^{L}\right)\left[\Pi_{2}\left(p^{L}, i^{L}\right)-\Pi_{2}\left(p\left(i^{L}\right), i^{L}\right)\right]=\delta \nu\left(P^{L}\right) \Pi_{2}\left(p^{L}, i^{L}\right)
$$

Equation (13) gives the maximum donation that is worthwhile from the viewpoint of the firm to enforce the price $p^{L}$. Now suppose that investment $i=i^{L}$ took place. Analogous to (13) is the following condition for a contract to be offered:

$$
s^{L}+s^{R}+i^{R} \leq \delta\left[\nu\left(P^{L}\right) \Pi_{2}\left(p^{L}, i^{R}\right)+\left(1-\nu\left(P^{L}\right)\right) \Pi_{2}\left(p^{R}, i^{R}\right)\right]
$$

Equation (14) gives the maximum total donations that are worthwhile from the viewpoint of the firm to enforce a price $p^{L}$ with party $\mathrm{L}$ and $p^{R}$ with party $\mathrm{R}$. In equilibrium these conditions on the maximum donations (14) (for two-party lobbying) or (13) (for one-party lobbying) must be satisfied for the contract to be worthwhile for the firms. In addition the donations must be sufficient to compensate the parties for a loss of consumer surplus that is anticipated by the informed voters, a condition given by (12).

Let $\eta\left(p^{j}\right)=-\frac{p^{j}}{q_{2}^{j}} \frac{d q_{2}^{j}}{d p^{j}}$ be the elasticity of demand. For analytical convenience we assume that the elasticity of demand is a constant denoted by $\eta$. In Appendix $\mathrm{C}$ we show that the regulated price offered to party $j=L, R$ is given by

$$
\begin{aligned}
\frac{p^{j}}{c} & =\frac{\delta \nu^{j} b(1-\theta) \eta}{\delta \nu^{j} b(1-\theta)(\eta-1)+d \theta} \quad \text { if donations are not 'excessive' } \\
& =\frac{p(0)}{c} \quad \text { otherwise }
\end{aligned}
$$

By 'excessive' donations we mean that the donation to the L-party $s^{L}$ lies below the upper bound implied by (13) below evaluated at the investment stage if only the L-party is lobbied and total donations $s^{L}+s^{R}$ lie below the upper bound given by (14) if both parties are lobbied; that is, donations are not so large as to make overall profits lower than in the case of zero donations, i.e. as to discourage the firm, who is seeking to prevent holdup, from entering into them in the first place. For a given investment made earlier and a 
proportion of informed voters $\theta,(15)$ then gives the optimal price contract offered by the firm with donations to support this platform given by (12) with equality (the condition for this constraint to bind is developed in Appendix C). An important feature of the contracts is that $P^{L}$ and therefore $\nu^{j}$ are independent of investment (See Appendix C).

\section{Stage 2: Investment.}

In an equilibrium where neither party signs a contract, the firm anticipates that profits will be zero whatever investment is made. Hence $i=0$ in this case. In an (anticipated) equilibrium where a contract is only signed with the $\mathrm{L}$ party, investment is chosen to maximize the discounted sum of profits $\Pi_{1}+\delta \nu\left(P^{L}\right) \Pi_{2}\left(p^{L}, i\right)$. Using (1), (9) and (2) and the fact established above that $P^{L}$ is independent of investment $i$ the first order conditions for this optimization can be written

$$
1=\delta \nu\left(P^{L}\right) f^{\prime}(i)
$$

to give an investment level $i=i^{L}$, say. If any investment occurs, then $i=i^{L}$ is chosen; but this is a local maximum. Investment results in a lower regulated price and it may be better for the firm to choose zero investment.

If a contract is signed with the $\mathrm{R}$ party as well, investment is chosen to maximize the discounted sum of profits:

$$
-k-i-s^{L}-s^{R}+\delta\left[\nu\left(P^{L}\right) \Pi_{2}\left(p^{L}\right)+\left(1-\nu\left(P^{L}\right)\right) \Pi_{2}\left(p^{R}\right)\right]
$$

Again using (2), the first order conditions for this optimization can be written

$$
1=\delta f^{\prime}\left(i^{R}\right)
$$

resulting in investment $i=i^{R}>i^{L}$, say.

We can now identify three equilibria depending on the proportion of informed voters: Type A (well-informed voters): $\theta \in\left(\hat{\theta}_{L}, 1\right]$. Then no contracts are signed, $p=p(0)$, $\Pi_{2}^{L}=\Pi_{2}^{R}=i=0$.

Type B (moderately-informed voters): $\theta \in\left(\hat{\theta}_{R}, \hat{\theta}_{L}\right]$. Then $\Pi_{2}^{L}, s^{L}>0 ; \Pi_{2}^{R}=s^{R}=0$. Investment $i=i^{L}$ is given by $1=\delta \nu^{L} f^{\prime}(i)$, provided the price is sufficiently high that the condition (13) holds, in which case investment is positive but below the first-best. Otherwise $i=0$. Let $\hat{p}=\hat{p}^{L}(i)$ be the solution to $\delta \nu^{L} \Pi_{2}(\hat{p}, i)=s^{L}+i$ and $\hat{p}=\hat{p}^{R}(i)$ be 
the solution to $\delta\left[\nu^{L} \Pi_{2}\left(\hat{p}^{L}, i\right)+\left(1-\nu^{L}\right) \Pi_{2}(\hat{p}, i)=s^{L}+s^{R}+i\right.$. Then thresholds $\hat{\theta}_{j}, j=L, R$ are given by

$$
\frac{\hat{p}^{j}\left(i^{j}\right)}{c}=\frac{\delta \nu^{j} b\left(1-\hat{\theta}_{j}\right) \eta}{\delta \nu^{j} b\left(1-\hat{\theta}_{j}\right)(\eta-1)+d \hat{\theta}_{j}}, j=L, R
$$

This equilibrium exists if $\hat{\theta}_{R}<\hat{\theta}_{L}$. From (18) this condition means

$$
\frac{\hat{p}^{L}\left(i^{L}\right)}{\nu^{L}}<\frac{\hat{p}^{R}\left(i^{R}\right)}{\nu^{R}}
$$

Although $\nu^{L}>\nu^{R}$, because $\hat{p}^{L}\left(i^{L}\right)>\hat{p}^{R}\left(i^{R}\right)$, (19) may not hold, for example as $\nu^{L}$ approaches $\nu^{R}$. Then the B equilibrium does not exist.

Type C (poorly-informed voters): $\theta \in\left(0, \hat{\theta}_{R}\right]$. Then $\Pi_{2}^{L}, s^{L}>0 ; \Pi_{2}^{R}, s^{R}>0$ and investment, $i=i^{R}$ is higher than in equilibrium $\mathrm{B}$ and given by $1=\delta f^{\prime}(i)$, provided the price is sufficiently high that condition (14) holds, in which case investment is first-best. Otherwise $i=i^{L}$ or $i=0$, depending on the conditions given for type B. As the proportion $\theta$ of informed voters becomes small, the regulated price rises which outweighs any welfare gain to the consumer from higher investment. We summarize these results in the following proposition.

\section{Proposition 1}

There are three possible equilibria, depending on how well-informed are the voters. In equilibrium A, a well-informed democracy, there are no lobbies and parties choose the regulated price to maximize consumer surplus. Rent is forced to zero and no investment occurs. In equilibrium B with a moderately informed electorate, only the incumbent party is lobbied resulting in a higher regulated price and positive rent if that party is elected. Investment can now be positive, but is below the first-best. In equilibrium $C$ with a poorly informed electorate, the opposition is also lobbied and implements a regulated price with positive rent, though both are less than that offered by the incumbent. Investment can now reach its first-best.

The intuition for this result is as follows: the central feature of the model is the division of voters into those who are well-informed in the sense that they understand the government's regulation policy and the remaining voters who make their voting decision based on the general impression of the parties' qualities gleaned during the election campaign. With only well-informed voters we have a standard hold-up problem resulting in underinvestment. The voting decision of badly informed voters depends on the relative size of 


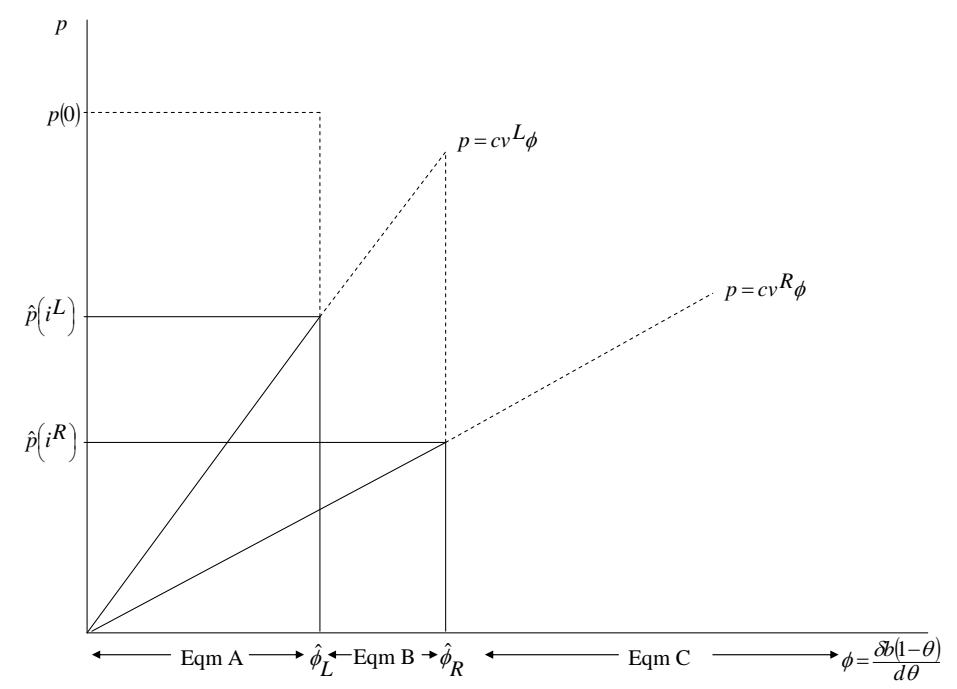

Figure 1: The Three Equilibria and Price Mark-up

the parties' election funds and it is this feature that creates incentives for the parties and firm to agree to implicit contracts linking political donations to an electoral mandate on the regulated price. An important assumption in this models and others of its genre is that parties attempt to carry out their mandate (though there is a degree of implementation uncertainty). This is the underlying commitment mechanism that enables the hold-up problem to be solved whilst giving the parties the discretion to change the price regime in response to a changing environment at each election. ${ }^{15}$

The political donations must be sufficient to compensate the political parties for a loss of votes arising from a high regulatory price relative to the 'opportunist' price that just satisfies the firm's current participation constraint (condition (12)). But donations must not be so large as to discourage the firm, who is seeking to prevent hold-up, from entering into them in the first place (conditions (13) and (14) for one-party and two-party lobbying respectively). The existence of a political equilibrium that raises investment depends on the existence of some political donation that lies between these bounds. If a high proportion of votes are well-informed such a political donation does not exist and the hold-up problem cannot be resolved by an election contract. As we withdraw information we arrive at an equilibrium with the less costly contract for the firm, which is one with

\footnotetext{
${ }^{15}$ This contrasts with the underlying commitment mechanism at play for Rogoff-delegation which is a commitment of either party to allowing the independence of the regulator once appointed.
} 
the incumbent L-party that is assumed to have an advantage in our set-up. Because of implementation uncertainty the firm cannot assume that the L-party mandate will be carried out and there is still a possibility of hold-up if the R-party's policy actually prevails. The firm takes this into account and investment is above the pure hold-up level of zero but below the first-best. As voter information falls further it then becomes advantageous for the firm to form contracts with both parties. Then whatever parties' policies are implemented in the elected assembly, hold-up is prevented. Anticipating this eventuality, the firm chooses the first-best investment level.

Figure 1 illustrates these equilibria by plotting $p$ against $\phi=\delta \eta b(1-\theta) /(d \theta)$ for the case where the price elasticity $\eta=1$, for which the relationship (15) is linear. Then pricecontracts are given by $p^{j}=c \nu^{j} \phi$ for $j=L, R$ for the two parties. ${ }^{16}$ At $\phi=\hat{\phi}_{L}, \theta=\hat{\theta}_{L}$ and the price $p=\hat{p}\left(i^{L}\right)$ is such that $\delta \nu^{L} \Pi_{2}\left(p, i^{L}\right)=s^{L}+i^{L}$; i.e., the price is just sufficient to provide a return on investment plus donation. The dashed line in the figure shows the movement of the regulated price. For the interval $\phi \in\left[0, \hat{\phi}_{L}\right]$ investment remains at zero and the regulated price is $p(0)$ where, we recall, $p(i)$ is the price at which $\Pi_{2}(p(i), 0)=0$. For $\phi \in\left[\hat{\phi}_{L}, \hat{\phi}_{R}\right]$, investment $i=i^{L}$, where $1=\nu^{L} \delta f^{\prime}(i)$, is optimal for the firm. The regulated price if the L-party is elected then falls and subsequently moves along $p^{L}=c \nu^{L} \phi$, until at $\phi=\hat{\phi}_{R}$ where $\theta=\hat{\theta}_{R}$ and a price-contract is also agreed with the R-party, the higher investment given by $i=i^{R}$, where $1=\delta f^{\prime}(i)$, becomes preferable to $i=i^{L}$. At $\phi=\hat{\phi}_{R}$, the regulated R-price is $p=\hat{p}\left(i^{R}\right)$ such that $\delta\left(\nu^{L} \Pi_{2}\left(\hat{p}^{L}, i^{R}\right)+\left(1-\nu^{L}\right) \Pi_{2}\left(p, i^{R}\right)=\right.$ $s^{L}+s^{R}+i^{L}$, and then moves along $p^{R}=c \nu^{R} \phi$. For $\phi>\hat{\phi}_{B}$, both L and R prices are rising and consumer surplus is falling. Eventually $\phi$ will reach a threshold at which the average price over the $\mathrm{L}$ and $\mathrm{R}$ parties exceeds $p(0)$ and then disinformation is counterproductive for the consumer. This point is pursued further in the welfare analysis of the next section.

\section{Rogoff-Delegation to an Independent Regulator}

Now suppose that voters are well-informed (i.e., $\theta=1$ ) so no lobbying takes place. Then from (8) vote share only depends on the consumer surplus and it is the latter that the parties must maximize. Without lobbying, there is platform convergence, and we can

\footnotetext{
${ }^{16}$ For $\eta>1$, the price-marginal cost curves are concave and are bounded above by the monopoly value $p=c /(1-1 / \eta)$
} 
now dispense with elections in our analysis. In this well-functioning democracy there is under-investment unless the government is able to commit to its regulated price before investment is made. But if no self-enforcing or external commitment mechanism is in place, can the under-investment problem be solved? The key to the delegation solution proposed here are two features: first, the existence of a heterogenity of regulator types with different preferences over consumer and producer surpluses and second, the ability of governments to commit to the independence of the regulator once appointed. ${ }^{17}$ Then a possible solution is provided by Rogoff-delegation, a second-best commitment mechanism in which the pricing decision is delegated to an independent regulator whose preferences do not necessarily coincide with those of the government. ${ }^{18}$ The significance of the independence of the regulator is that the choice of regulator and their decisions cannot be over-ruled after the sunk investment has been made by the firm.

The timing of events for the delegation game is as follows:

1. The government delegates price regulation to an independent regulator with objective function:

$$
W(p)+\alpha \Pi_{2}(p, i)
$$

in period 2, where $\alpha \geq 1$ measures the extent to which the regulator is pro-industry. In the previous political equilibrium if the voters are well-informed, the government responds by maximizing (20) with $\alpha=0$. Now we allow the possibility that voters may own the regulated firm in which case a utilitarian social welfare with $\alpha=1$ is appropriate.

\footnotetext{
${ }^{17}$ The change of stance brought about by new regulators can be illustrated by the descriptions of Tom Winsor when he was announced as the UK's new rail regulator in 1999: "a 'hawkish' lawyer [appointed] to toughen up rail regulation and make life more difficult for ... the train operating companies" (see Daily Telegraph, 24 March, 1999; see also Daily Telegraph, 28 May, 1999. In Spain the public track record of the first electricity regulator, Miguel Ángel Fernández Ordóñez, was very different from the track record of the second, Pedro Meroño. The first, appointed by the Socialist Party in the early 90s, was an economist leader of the liberal wing of the party, and had previously been the Chairman of the Anti-trust authority (Tribunal de Defensa de la Competencia). The second, appointed by the Popular Party in the late 90s, was a lawyer and had been a member of the Board of Directors of the incumbent state owned electricity firm, Endesa.

${ }^{18}$ Where firms have private information, Levine and Rickman (2002) examine the role of delegation as a means of ameliorating both the 'ratchet-effect' and the the hold-up problem.
} 
2. At the beginning of period 1 , the firm inherits a capital stock with per period fixed $\operatorname{costs} k$.

3. The firm chooses investment $i$.

4. At the beginning of period 2, the regulator chooses $p$ to maximize (20).

Solving for a backwards induction equilibrium, at stage 4 the independent regulator solves the problem:

$$
\text { Given i maximize w.r.t } \mathrm{p} \quad\left[W(p)+\alpha \Pi_{2}(p, i)\right]
$$

subject to $\Pi_{2}(p, i)=(p-c) \psi(p)-k+f(i) \geq 0$.

The solution to this problem follows as for stage 2 of the political equilibrium. The unconstrained optimization problem leads to a Lerner index for the independent regulator of type $\alpha$

$$
L=L(p)=\frac{p-c}{p}=\frac{\alpha-1}{\alpha \eta(p)}
$$

As before assume a constant elasticity $\eta(p)=\eta$. Then the regulated price by the independent regulator is given by

$$
p^{I}=\frac{c \alpha \eta}{\alpha(\eta-1)+1}=p^{I}(\alpha)
$$

if the second-period participation constraint does not bind (i.e., $\Pi_{2}\left(p^{I}(\alpha), i\right)>0$ ). It should be noted that $p^{I}$ is independent of investment (as were the price contracts in the previous lobbying equilibrium). If the constraint does bind then the regulated price is a function of investment $p=p(i)$ where $p(i)$ is the solution to $\Pi_{2}(p(i), i)=0$. Clearly $\Pi_{2}\left(p^{I}, i\right)<0$ if $\alpha=1$ (in which case $p^{I}=c$ ), the case of a representative regulator. But as $\alpha$ increases, given $i$, eventually the price given by (23) is high enough to give non-negative rent at some threshold value $\alpha=\hat{\alpha}(i)>1$. Thus $\hat{\alpha}(i)$ is defined by $p^{I}(\hat{\alpha})=p(i)$. Using (23) this gives

$$
\hat{\alpha}(i)=\frac{1}{1-\eta L(p(i))}
$$

Since $L \in\left[0, \frac{1}{\eta}\right]$ it follows that $\hat{\alpha} \in[1, \infty)$.

Given this choice of price at stage 4 , at stage 3 if the participation constraint binds in period 2 and $\Pi_{2}(p(i), i)=0$ for a given investment, then the firm does not invest. When $\alpha>\hat{\alpha}(i)$ the constraint ceases to bind and the price $p=p^{I}$ given by (23). This increases 
with $\alpha$, which increases the rent. Now an incentive to invest may exist. If the firm does choose to invest it will achieve a maximum of the 2-period rents

$$
-k-i+\delta\left[\left(p^{I}-c\right) \psi\left(p^{I}\right)-k+f(i)\right]
$$

at $i=i^{F B}>0$ (the first-best) satisfying

$$
1=\delta f^{\prime}(i)
$$

However the firm may also choose not to invest. Given the regulated second-period price, $i=i^{F B}$ is preferable to $i=0$ only if the regulated price $p^{I}$ is sufficiently high to ensure that

$$
i^{F B} \leq \delta\left[\Pi_{2}\left(p^{I}(\alpha), i^{F B}\right)-\Pi_{2}\left(p^{I}(\alpha), 0\right)\right]
$$

subject to $\Pi_{2}\left(p^{I}(\alpha), 0\right) \geq 0$, the second-period participation constraint following no investment. If the latter condition does bind (26) becomes:

$$
i^{F B} \leq \delta \Pi_{2}\left(p^{I}(\alpha), i^{F B}\right)
$$

This occurs when $\alpha>\bar{\alpha}>\hat{\alpha}$, say where $\bar{\alpha}>\hat{\alpha}$. Notice that the condition (27) is equivalent to (13) for the single-party contract case as donations $s^{L} \rightarrow 0$ and implementation uncertainty disappears $\left(\nu^{L} \rightarrow 1\right)$. As $\alpha$ increases, price increases, and at some point, say at $\tilde{\alpha}$, a situation is reached so that price is so high that delegation is counterproductive, yielding a social welfare level that is lower than the social welfare achieved with no delegation and under-investment (but price just high enough as to break even). Proposition 2 summarizes these results.

\section{Proposition 2}

Delegation to a sufficiently pro-industry regulator with $\alpha>\bar{\alpha}>\hat{\alpha}\left(i^{F B}\right)>1$ results in the first-best investment outcome. For some interval, $\alpha \in[\bar{\alpha}, \tilde{\alpha}]$, welfare under delegation is higher than that under a representative regulator. For $\alpha>\tilde{\alpha}$, the regulator is too pro-firm and then delegation becomes counterproductive.

The intuition for this result is quite simple: delegation to a relatively pro-industry independent regulator shifts its preferences closer to the interests of the firm. If this shift is sufficient then the incentive to hold-up the firm disappears and first-best investment results. At this point the regulated price is lower than that without investment so the 
consumer gains. However, as the regulator becomes more pro-industry the regulated price rises to the point where it is higher than that without investment and any gain to the consumer from higher investment disappears.

Finally we note that we have formulated conditions for an equivalence between the political and delegation equilibria arising from the fact that both equilibria shift the preferences of the regulatory authority. Consider the case where the incumbent party has no advantage. Then $a=0, \nu_{L}=\nu_{R}=\frac{1}{2}$ and the same contract is signed with both parties. By equating the Lerner indices (15) and (22) we can see that all details of the two equilibria in the second period are identical if the pro-industry regulator is chosen with $\alpha=\delta \nu b(1-\theta) / d \theta$, except for the existence of lobbying costs. The existence of lobbying costs make prices higher, but the same first best investment levels can be achieved in both cases. To summarize we have:

\section{Proposition 3}

If the incumbent party has no advantage and $\nu_{L}=\nu_{R}=\frac{1}{2}$, then the political and delegation equilibria are equivalent, apart from lobbying costs incurred by the firm, if $\alpha=\delta \nu b(1-\theta) / d \theta$.

The lobbying model is solved for a given level of voter information, but we emphasize that there is an optimal welfare maximizing level of information, that could be enforced by a benevolent government or a constitutional congress. We do not model that explicitly; in practice, some societies might evolve as to find this level of information or $\alpha$ in the absence of other commitment mechanisms.

We have shown that 'independence' solution and the 'limited information' solutions are equivalent, except for the political legitimacy problems of capture and for the fact that there are lobbying costs associated with the latter. Of course this means that they are not exactly equivalent because of the existence of lobbying costs, although both solutions have the potential of achieving first best investment levels. Our model provides some insights into when lobbying costs may make the difference between the lobbying equilibrium and the delegation equilibrium large. Lobbying costs vary from one country to another. In our model, the solution of stage 4 of the game (equation 14) establishes that lobbying expenditures depend negatively on parameter $\mathrm{b}$ and positively on parameter $\theta$. The latter is the proportion of voters who are informed about regulatory policies, which will obviously 
vary across countries. Parameter $b$ is the degree to which lobbying expenditures translate into efficient electoral campaigning. More generally, it can be interpreted as how lobbying contributions can be translated into something valuable for political parties or policy makers. This will factor in what Laffont (2005) calls the cost of side transfers between the firm and the regulator (in the case of the lobbying model, the governing political party), which includes the costs of being discovered if direct transfers are illegal as well as the need often to use indirect transfers that are less efficient than monetary transfers.

\section{Regulatory Governance in Practice and Empirical Evi- dence}

In this section, we first compare the three potential solutions to under-investment offered in the earlier sections (externally imposed commitment to a price regime, partial capture through a rationed level of information and delegation to an independent regulator of the right 'type'), presenting some examples from the real world. Second, we discuss the empirical evidence linking the regulatory environment to outcomes.

\subsection{Theoretical Results and Real World Practice}

The theoretical results for a political equilibrium where a proportion of voters are uninformed and the regulator is in effect the government, and a delegation equilibrium where the regulator is independent, have the following empirical implications: first, externally imposed commitment, rationed information and regulatory independence are imperfect substitutes. ${ }^{19}$ In the presence of sunk costs that must be covered by regulated prices, the ability of both the regulator and the firm to commit to future policies delivers first best price and investment. Commitment in utilities regulation may be achieved for example through constitutional constraints, through very detailed legislation, or through the development of a judicial tradition, such as the 'fair' rate of return tradition in the U.S. The theoretical literature reviewed above suggests that the first-best outcome may be sustained as either trigger strategy or 'reputational' equilibrium even in the absence of

\footnotetext{
${ }^{19}$ The idea of substitutability between commitment and rational ignorance has also been put forward by Faure-Grimaud (2002). In his model, the regulator prefers to commit to not setting up a monitoring structure and instead rely on noisy information provided by the stock market.
} 
these constraints. However, as we have argued, there are logical problems with these equilibria. Then under-investment may be alleviated through an optimal degree of voters' information or through regulatory independence. Regulatory independence may deliver higher welfare than the information mechanism (which depends on wasteful rent-seeking activities). However, some studies have shown that in some countries independence may not be credible or sustainable (see Guasch and Spiller, 1999, and Gual and Trillas, 2004 and 2006), and hence the relevance of the partial capture through the 'rationed voters' information case.

Second, in the absence of externally enforced commitment, capture or regulatory independence become more necessary to alleviate under-investment the larger the returns to investment and the higher the discount factor. If the investment in regulated sectors is crucial for the development of a country, some mechanism to alleviate under-investment becomes necessary. On the contrary, if the country already has a high level of physical infrastructure, the mechanisms to alleviate under-investment become less important. Moreover, when agents attach a high value to the future (due to political stability or to low interest rates, for example) the welfare-enhancing properties of the information mechanism or regulatory independence become more evident.

The institutional mix in every country develops endogenously depending on more primitive political and economic parameters. The model presented lays the preliminary theoretical foundations of a research agenda that makes more precise the idea that effective regulation depends on the institutional endowment of each country (see Levy and Spiller, 1996). The role of the judiciary, the use of contracts, the existence of checks and balances, the reputation of the civil service, the administrative procedures and the importance of informal norms and institutions have also been suggested as possible contributors to alleviate the under-investment problem.

We give three examples of situations that look close to the different solutions to the under-investment problem, namely externally enforced commitment, regulator independence and capture with partial voter disinformation.

In Chile there is commitment through very detailed legislation drafted in the late 1980's and through the reputation of the government and Chilean institutions for respecting contracts. Chile, is an example of a successful early liberalizer and privatizer that has been 
able to attract a great amount of foreign investment into network industries, regulators are cabinet ministers, and hence there is no regulator independence. However, legislation prescribes with great detail the formulae that price reviews have to follow and the forward looking efficiency criteria that must be taken into account. In addition, a political system based on the coexistence of a President and two legislative chambers, together with some details of an electoral process that favours two broad coalitions, make legislative change very difficult and slow. Interestingly, experts have suggested that progress should be made towards more independent regulatory agencies. Some of the problems in Chilean privatization, like the lack of credibility of commitments not to expand the length of concession contracts, could be alleviated with independent regulators separate from the ministries in charge of planning for infrastructure expansion. Other reasons that have been suggested for increasing the degree of regulator independence are the need to respond to unforeseen contingencies, such as the severe drought of the late 1990's that caused serious shortages in a basically hydro-based electricity system; or the need to overcome the lack of expertise in the public sector. These and related issues are further developed among other sources in Basañes et al. (2002).

The UK is characterised by independent regulation subject to contract licences(see, for example, Armstrong et al (1994)). The independence of regulators is established in primary legislation. There are regulatory "offices" in telecommunications (OFCOM, previously OFTEL), electricity (OFGEM, previously OFFER) and water (OFWAT), headed by Director Generals that have a high degree of autonomy to conduct regulatory price reviews and overlook the development of competition in some segments of the industries. The system was set up by the Conservative Thatcher and Major governments in the mid and late 1980's, and the Labour government has basically kept it with minor changes in its independence features.

While in Spain there is partially captured non-independent regulation. The White Book on electricity generation reform in Spain (Pérez Arriaga, 2005) explains that the regulatory tradition (going back to the military dictatorship between 1939 and 1975) in Spain is one of negotiation between firms and government behind close doors. This document presents evidence consistent with inefficiency of distribution regulation, and a recent reduction in the monitoring role of CNE (the energy regulator). The CNE in Spain is basically not 
independent from government, although it has a sizeable budget, and has been criticized for stopping at some point to report for example on market power in the electricity pool. This suggests that the government fine-tunes (depending on exogenous time dependent parameters and the time dependent ability to commit) the degree of information, using procedures or informal rules and the budget of the agency. Still, the White Book also shows that in Spain investment is relatively high and there has not been any episode of systemic black-out as in other countries; critics such as the author of the White Book suggest that the system is inefficient (prices do not reflect social costs, consumption is excessive, firms do not operate at best practice) but apparently it solves the under-investment problem. Of course, voter disinformation and capture do have a cost in terms of other objectives such as social legitimacy or ethical considerations.

\subsection{Empirical Evidence}

A growing number of empirical studies consider the outcome of different types of regulators in different industries and countries. The common characteristics of regulators that produce first best results are that the regulatory environment encourages commitment and allows the investor to be fully compensated for the opportunity cost of their investment. Wallsten (1999) quantifies the effects of a separate regulatory authority in a cross-section of countries. However, he acknowledges that the lack of detail ${ }^{20}$ in their measure of institutional characteristics is an important limitation of their conclusions. Wallsten concludes that privatization combined with a separate regulatory authority (which is interpreted as signalling a move towards regulatory reform and is measured as a dummy variable that does not distinguish between independent separate authorities and non-independent separate authorities) has a significantly positive effect on network expansion and labour productivity in telecommunications.

Henisz and Zelner (2001) use an index of political commitment which has a positively significant effect on network deployment. Their index is not specific to the regulated network sectors, although they use it to test the hypothesis for the telecommunications industry. Consequently, they admit that a more detailed study of the regulatory institutions

\footnotetext{
${ }^{20}$ Gual and Trillas (2004 and 2006) provide much more detail, building an index of independence, but without robust results in terms of the impact of such independence. However, they compute the index only for one year, 1998.
} 
is warranted.

The effectiveness of firm lobbying in the cellular industry of the US is tested by Duso (2005). He shows that where regulation took place, there was no significant reduction in phone tariffs due to the success of firms' lobbying activities. Firms were able to avoid regulation in those markets where it would have been most effective.

Holburn and Spiller (2002) use a panel data set of rate reviews of the US electric utilities to determine the impact of consumer advocates and Public Utility Commissioners on regulatory policy and utility strategy. Elected commissioners and consumer advocates were found to stave off rate reviews and grant lower returns on equity. A later study using a panel data set also from the US electric industry by Guerriero (2003) analyzes the degree of judical accountability and outcomes of a regulated industry. He finds that states where

judges are elected have lower electricity prices as they are less likely to pass through cost changes into prices.

Although the empirical evidence is relatively limited (especially when compared to the literature on Central Bank Independence), the general conclusion is that isolating regulators from political pressures and from impatient consumers can have a positive effect on private investment, which is consistent with the model presented above. More research is needed on the political sustainability of such delegation and on the details of complementary or alternative governance arrangements.

\section{Conclusions}

The time inconsistency problem derived from the existence of sunk investments in network industries has been historically alleviated through different imperfect means that try to internalize the problem: public ownership is an example of this, which basically merges the bodies that take both price and investment decisions. We have compared two alternative settings to alleviate the same problem, one with a politically constrained regulator and one with an independent relatively 'pro-industry' regulator, and shown that, except for the existence of lobbying costs, there is an economic equivalence among them, given that the 'right' type of regulator can be found and that there is the 'right' amount of electoral 
transparency $^{21}$ where the optimal proportion of voters are informed about regulatory policies. The model illustrates under which conditions and at what price the underinvestment problem can be alleviated. In both cases, capture with a fraction of uninformed voters and regulatory independence, the price to be paid for re-establishing first best investment may be a higher price than the first best and high rents for the regulated firm. The strategic value of keeping a fraction of voters uninformed and of appointing a pro-industry regulator increases with the returns to investment and with the discount factor.

Our results throw some light on how a regulatory regime might achieve effective regulation whether through government-dependent or independent regulators. Effective regulation must achieve: first, socially optimal levels of both investment and effort. This latter rules out direct controls or 'rate of return' regulation. Second, the consumer should benefit from higher investment through lower prices. Our paper shows that with discretion, a government-dependent regulator that provides the public with just the right amount of information, or delegation to an independent regulator of just the right type will achieve first best investment at possibly some cost in terms of prices. There is also a cost in terms of political legitimacy, which is obvious in the case of capture, and which may arise in practice in the case of independent regulators, if they do not behave with adequate procedures and accountability: they should have limited and accountable discretion.

This, in a sense, is a positive rather than normative result. To derive normative conclusions we note that we have relocated the problem as one of choosing the correct amount of political transparency or the correct type of regulator. The latter problem seems easier to solve and avoids the costs of lobbying. As we have argued regulators have track records. New regulators should be aware of the problem posed in our model and be prepared to build up a reputation for achieving the 'right balance between the needs of consumers and the firm' (i.e., a reputation for having the right $\alpha$ ). One could see this process in terms of 'as if' Rogoff-delegation rather than the literal interpretation of choosing the right type. Some formal modelling of the process by which regulators acquire reputation for being of a particular type and, at the same time, governments build up a reputation for respecting their independence, might be worthwhile in future work.

\footnotetext{
${ }^{21}$ There is a large literature on the costs and benefits of transparency in the conduct of monetary policy (see for example, Faust and Svensson (2001) and the survey by Geraats (2002)).
} 
The setting presented here has focused on very stylized regulatory characteristics. We have studied regulation under complete information, but our delegation approach is also appropriate where the firm possesses asymmetric information. Then even without the investment issue, delegation can alleviate the 'ratchet effect'; with delegation addressing both the ratchet effect and the under-investment problem. ${ }^{22}$

\section{Acknowledgements}

We are grateful to two anonymous referees and B. Caillaud as editor, for helpful comments and suggestions. All remaining errors are ours.

\section{References}

[1] al-Nowaihi, A., Levine, P., 1994. Can Reputation Resolve the Monetary Policy Credibility Problem? Journal of Monetary Economics 33, 355-380.

[2] Armstrong, M., Cowan, M., Vickers, J., 1994. Regulatory Reform, Economic Analysis and British Experience. The MIT Press.

[3] Armstrong, M., Sappington, D., 2003. Recent Developments in The Theory of Regulation, forthcoming in Handbook of Industrial Organization, vol. III.

[4] Armstrong, M., Vickers, J., 1996. Regulatory Reform in Telecommunications in Central and Eastern Europe. Economics of Transition 4(2), 295-318.

[5] Basañes, F., Saavedra, E., Soto, R., 2002. Post-Privatization Renegotiations and Disputes in Chile, in Basañes, R. and R. Willig, eds., Second-Generation Reforms in Infrastructure Services, Inter-American Development Bank.

[6] Besanko, D., Spulber, D., 1992. Sequential Equilibrium Investment by Regulated Firms. RAND Journal of Economics 23(2), 153-170.

[7] Besley, T., Coate, S., 2003. Elected versus Appointed Regulators: Theory and Evidence. Journal of the European Economic Association 1(5), 1176-1206.

\footnotetext{
${ }^{22}$ See Levine and Rickman (2002).
} 
[8] Boyer, M., Laffont, J-J., 1999. Toward a Political Theory of the Emergence of Environmental Incentive Regulation. RAND Journal of Economics 30(1), 137-157.

[9] Che, Y.-K., 1995. Revolving Doors and The Optimal Tolerance for Agency Collusion. RAND Journal of Economics 26(3), 378-397.

[10] de Figueiredo, Jr., Rui J.P., Spiller, P. T., Urbiztondo, S., 1999. An Informational Perspective on Adminitrative Procedures. Journal of Law, Economics and Organization 15(1), 283-305.

[11] Duso, T., 2005. Lobbying and Regulation in a Political Economy: Evidence from the US Cellular Industry. Public Choice 122 (3-4), 251-276.

[12] Faust, J., Svensson, L., 2001. Transparency and Credibility: Monetary Policy with Unobservable Goals. International Economic Review 42(2), 369-397.

[13] Faure-Grimaud, A., 2002. Using Stock Price Information to Regulate Firms. Review of Economic Studies 69(1), 169-90.

[14] Fox, Loren, 2003. Enron. The Rise and Fall. John Wiley and Sons.

[15] Geraats, P.M., 2002. Central Bank Transparency. The Economic Journal 112(483), F532-565.

[16] Gilbert, R.J., Newbery, D.M., 1994. The Dynamic Efficiency of Regulatory Constitutions. RAND Journal of Economics 25(4), 538-554.

[17] Grossman, G. M., Helpman, E., 1996. Electoral Competition and Special Interests Politics. Review of Economic Studies 63, 265-286.

[18] Grossman, G. M., Helpman, E., 2001. Special Interest Politics. The MIT Press.

[19] Gual, J., Trillas, F., 2004. Telecommunications Policies: Determinants and Impact. Discussion Paper 4578 CEPR, London.

[20] Gual, J., Trillas, F., 2006. Telecommunications Policies: Measaurement and Determinants. Review of Network Economics 5(2), 249-272. 
[21] Guasch, J. L., Spiller, P., 1999. Managing the Regulatory Process: Design, Concepts, Issues and the Latin American Caribbean Story, The World Bank, Washington DC.

[22] Guerriero, C., 2003. Dependent Controllers and Regulation Policies: Theory and Evidence, mimeo.

[23] Henisz, W. J., Zelner, B. A., 2001. The Institutional Environment for Telecommunications Investment. Journal of Economics and Management Strategy 10(1), 123-147.

[24] Holburn, G.L.F., Spiller, P.T., 2002. Interest Group Representation in Administrative Institutions: The Impact of Consumer Advocates and Elected Commissioners on Regulatory Policy in the United States. Energy Policy and Economics Working Paper 002, October, www.ucei.org.

[25] International Telecommunications Union, 2002. Effective Regulation: Trends in Telecommunications Reform, Switzerland.

[26] Joskow, P. L., 2006. Natural Monopolies, in Handbook of Law and Economics, Polinsky, A.M. and S. Shavell, eds, Elsevier, forthcoming.

[27] Laffont, J-J., 2005. Regulation and Development, Cambridge University Press.

[28] Laffont, J-J., Tirole, J., 1993. A Theory of Incentives in Procurement and Regulation. Cambrige and London: The MIT Press.

[29] Levine, P., Rickman, N., 2002. Price Regulation, Investment and the Commitment Problem. CEPR Discussion Paper No. 3200.

[30] Levine, P., Stern. J., and Trillas, F., 2005. Utility price regulation and time inconsistency: comparisons with monetary policy. Oxford Economic Papers 57(3), 447-478.

[31] Levy, B., Spiller, P.T., eds., 1996. Regulations, Institutions and Commitment. Cambridge: Cambridge University Press.

[32] Newbery, D.M., 1999. Privatization, Restructuring and Regulation of Network Industries, Cambridge and London: The MIT Press.

[33] Pérez Arriaga, I., 2005. White Book of Electricity Generation in Spain, Ministerio de Industria. 
[34] Rogoff, K., 1985. The Optimal Degree of Commitment to an Intermediate Monetary Target. Quarterly Journal of Economics 100(4), 1169-1189.

[35] Salant, D. J., 1995. Behind The Revolving Door: A New View of Public Utility Regulation. RAND Journal of Economics 26(3), 362-377.

[36] Salant, D., Woroch,G., 1992. Trigger Price Regulation. RAND Journal of Economics $23,29-51$.

[37] Sloof, R., 2000. Interest Group Lobbying and The Delegation of Policy Authority. Economics and Politics 12(3), 247-274.

[38] Smith, W.,1997. Utility Regulators -The Independence Debate. Public Policy for The Private Sector Note 127. World Bank, Washington, D.C.

[39] Spiller, P. T., 1990. Politicians, Interest Groups and Regulators: A MultiplePrincipals Agency Theory of Regulation, or "Let Them Be Bribed," Journal of Law and Economics XXXIII, 65-101.

[40] Spulber, D. F., Besanko, D., 1992. Delegation, Commitment, and the Regulatory Mandate. Journal of Law, Economics and Organization 8(1), 126-154.

[41] Urbiztondo, S., 1994. Investment without Regulatory Commitment: The Case of Elastic Demand. Journal of Regulatory Economics 6, 87-96.

[42] Wallsten, S., 2001. An Empirical Analysis of Competition, Privatization and Regulation in Africa and Latin America. Journal of Industrial Economics 49(1), 1-19. 


\section{A Summary of Notation}

\begin{tabular}{|c|c|}
\hline$\left(p^{j}, s^{j}\right)$ & $\begin{array}{l}\text { regulated price contract and lobbying contribution } \\
\text { offered by the firm to party } j=L, R .\end{array}$ \\
\hline$q=\psi(p)$ & second-period output given by inverse demand function of price $p$. \\
\hline$\eta=-\frac{p d q}{q d p}$ & elasticity of demand (assumed constant) \\
\hline$k$ & fixed per period cost in period 1 \\
\hline$i$ & period 1 investment \\
\hline$i^{j}, j=L, R$ & period 1 investment associated with contract $j$ \\
\hline$k-f(i)$ & $\begin{array}{l}\text { fixed per period cost in period } 2 \\
\text { where } f(0)=0, f^{\prime}(0)=\infty, f^{\prime}>0, f^{\prime \prime}<0\end{array}$ \\
\hline$c$ & second-period marginal cost of production \\
\hline$\Pi_{t}, t=1,2$ & period $t$ profits of the firm \\
\hline$\delta$ & discount factor \\
\hline$\nu^{j}=\nu^{j}\left(P^{j}\right)$ & $\begin{array}{c}\text { probability of party } j=L, R \text { implementing pricing policy } p^{j} \\
\text { as a function of vote share } P^{j}\end{array}$ \\
\hline$\theta$ & proportion of informed voters \\
\hline$W(p)$ & net consumer surplus as function of price $p$ \\
\hline$d, b$ & $\begin{array}{l}\text { scaling parameters to convert consumer surplus } \\
\text { and lobbying contributions into votes }\end{array}$ \\
\hline$a$ & $\begin{array}{c}\text { The probability of the incumbent with an identical platform } \\
\text { winning the election minus } \frac{1}{2}\end{array}$ \\
\hline$\alpha$ & regulator type in delegation equilibrium \\
\hline
\end{tabular}

Table 1. Summary of Notation .

\section{B A Simple Model of Binding Electoral Platforms}

As in the paper we assume parties seek to maximize representation and this is achieved in any one period through maximizing voter shares $P_{t}$. A plausible and convenient intertemporal objective at time 0 is to maximize a discounted sum of votes $\sum_{t=0}^{\infty} \beta^{t} P_{t}$ where $\beta$ is a discount factor. 
Suppose with electoral commitment and no reneging the party expects to achieve votes $\left\{P_{t}^{C}\right\}, t=0,1, \cdots$. In any period of office it may renege on this commitment with an immediate gain in representation (perhaps through defections or concessions to rebels) worth a proportional gain in votes of $g \%$. But in the subsequent elections the loss of reputation for commitment loses the party $\ell \%$ votes. Then the no-deviation condition for commitment to be preferred to reneging is

$$
\sum_{t=0}^{\infty} \beta^{t} P_{t}^{C}>(1+g) P_{0}^{C}+\sum_{t=1}^{\infty} \beta^{t}(1-\ell) P_{t}^{C}
$$

Assume that $P_{t}^{C}=P^{C}$, a constant. Then (B.1) becomes

$$
\ell \sum_{t=1}^{\infty} \beta^{t}>g
$$

The left-hand-side of (B.2) is the infinite-period punishment arising from the loss of reputation for commitment to election platforms and the right-hand-side is the one-period temptation representing the gain from reneging. A little algebraic manipulation then gives this condition as

$$
\beta>\frac{g}{g+\ell}
$$

How stringent is this condition for election platforms to be binding? The electoral cycle in democracies is typically 4 or 5 years. With an annual discount rate of 0.95 this gives $\beta=0.95^{5}=0.77$ at least. If voting gains are balanced by voting losses. i.e., $g=\ell$, then

the right-hand-side of (B.3) equals $\frac{1}{2}$ and the condition easily holds. In fact one might well expect $\ell>g$, so we conclude that reputational considerations support the assumption in the paper that electoral platforms can be binding.

\section{The Choice of Contract at Stage 3 of the Lobbying Game}

The constraint (12) must bind for $j=L$ if

$$
\frac{\partial \Theta}{\partial s^{L}}=\delta \nu^{\prime}\left(P^{L}\right) \frac{\partial P^{L}}{\partial s^{L}}\left[\Pi_{2}\left(p^{L}, i\right)-\Pi_{2}\left(p^{R}, i\right)\right]-1 \leq 0
$$

where from $(8) \frac{\partial P^{L}}{\partial s^{L}}=(1-\theta) b$; i.e., if the marginal benefit from the first dollar of extra contribution to $L$ is not higher than its marginal cost. Similarly (12) binds for $j=R$ if

$$
\frac{\partial \Theta}{\partial s^{R}}=\delta \nu^{\prime}\left(P^{R}\right)(1-\theta) b\left[\Pi_{2}\left(p^{L}, i\right)-\Pi_{2}\left(p^{R}, i\right)\right]-1 \leq 0
$$


If party $L$ is the more popular party $(a>0)$, it follows that $P^{L}>P^{R}$. Therefore since $\nu^{\prime \prime}>0$, it follows that $\nu^{\prime}\left(P^{R}\right)<\nu^{\prime}\left(P^{L}\right)$. Hence from (C.1) and (C.2), $\frac{\partial \Theta}{\partial s^{R}}<\frac{\partial \Theta}{\partial s^{L}}$ and if (C.1) holds for party L, condition (C.2) must hold for the R party too. In what follows we examine equilibria for which $b \nu^{\prime}\left(P^{j}\right)$ is sufficiently small so as (C.1) and therefore (C.2) hold. Then (12) holds with equality and from (10) $P^{L}=\frac{1}{2}+a$, i.e., $P^{L}$ is independent of $s^{j}$ and investment which we use in the investment decision at stage 2.

Using (12) with equality, the optimal contract for the firm to offer to party j implements a price $p=p^{j}$ to maximize:

$$
\delta \nu^{j} \Pi_{2}\left(p^{j}, i\right)-s^{j}=\delta \nu^{j} \Pi_{2}(p, i)+\frac{d \theta}{b(1-\theta} W\left(p^{j}\right)+\text { constant }
$$

subject to (13) if only the L-party is lobbied, and (14) if both parties are lobbied.

The first order condition for the unconstrained optimization problem is

$$
\delta \nu^{j} \frac{\partial \Pi_{2}}{\partial p^{j}}+\frac{d \theta}{b(1-\theta)} W^{\prime}\left(p^{j}\right)=0
$$

Using the fact that the net consumer surplus is given by

$$
W\left(p^{j}\right)=\int_{p^{j}}^{\infty} \psi^{-1}\left(p^{\prime}\right) d p^{\prime}
$$

we have that $W^{\prime}\left(p^{j}\right)=-q^{j}$. Using this result and $\frac{\partial \Pi_{2}}{\partial p^{j}}=q^{j}+\left(p^{j}-c\right) \frac{d q^{j}}{d p^{j}}$, (C.3) becomes

$$
L^{j}=\frac{p^{j}-c}{p^{j}}=\frac{\delta \nu^{j} b(1-\theta)-d \theta}{\delta \nu^{j} b(1-\theta) \eta\left(p^{j}\right)}
$$

where $L^{j}$ is the Lerner index for party $\mathrm{j}$ and $\eta\left(p^{j}\right)=-\frac{p^{j}}{q^{j}} \frac{d q^{j}}{d p^{j}}$ is the elasticity of demand. Assume that the elasticity of demand is a constant denoted by $\eta$. We can now characterize the regulated price and the choice of investment by the firm in a political equilibrium as (15) in the main text. 